\title{
How Consumers Shop in Virtual Reality? How It Works?
}

\author{
Hiu-fai Lau*, Chi-wai Kan, Kung-wong Lau \\ Institute of Textiles and Clothing, The Hong Kong Polytechnic University, Hung Hom, Kowloon, \\ Hong Kong, People's Republic of China \\ *Corresponding Author: lau.hiu.fai@gmail.com
}

Copyright @ 2013 Horizon Research Publishing All rights reserved.

\begin{abstract}
The tremendous development of technological wave, in particular to virtual technology, has brought shopping activities into a new era. Current research is keen to investigate the relationships between consumers and technology in diverse virtual environments. This article aims to discuss the future directions for shopping practices in virtual worlds. Based on the scope of utilizing virtual technology in shopping practices, our research team investigates how consumers use virtual technology in shopping activities from reviewing prior research of consumer behavior and technological development. Our team highlights the importance of interactivity between virtual technology and consumers. This paper triggers further investigations in the area of (1) the instrumental relationships between the technology and consumer, (2) the connectivity to consumers, and (3) the consumers' perception of shopping in virtual environments and the daily practices in bricks-and-mortar shopping. The research team urges the needs of investigating shopping experiences in virtual worlds for the mentioned areas.
\end{abstract}

Keywords Consumers' Shopping Experiences, Interaction, Virtual Technology, Virtual Reality

\section{Introduction}

In the last decade, marketers widely utilize virtual technology in shopping practices to attract consumers' attention. The relationships between virtual technology and consumers are now closely associated, as marketers develop diverse shopping strategies in virtual environments which aim to enhance consumers' shopping experiences [1-5]. Numerous researches indicate that different consumers' experiences are able to induce consumers' shopping engagement [6-14]. Therefore, many research are currently focusing on understanding how the use of virtual technology affect consumers' experiences in order to attract consumers' shopping intention [15-18]. Many research claim that the use of virtual technology provides consumer with unique shopping experience, such as telepresence [5, 19-21], high level of interactivity [22] and multisensory feedback [23, 24].
With the boost of virtual technology development, consumers' shopping experience would be enriched [18].

Therefore, scholars urge the needs to focus on the consumers in virtual worlds [16, 25-32]. Many research investigate the relationships between the application of virtual technology and consumers' experiences, which aim to improve future technology development, such as enhancing consumers' telepresence [20,33], understanding the sense-making of consumer in virtual environments [34], applying clues to induce consumer shopping engagement [16], enriching consumers' sensorial experiences [23, 24], co-creating virtual worlds [35], enhancing consumers' spatial experience in VEs [36, 37], and understanding consumers' purchasing intention [5, 38-40].

In order to know how consumers shop in virtual reality, our research team investigates how consumers use virtual technology in shopping activities. Based on the scope of utilizing virtual technology in shopping practices and consumer behavior, our team reviews prior research from the consumer behavior and technological development perspective. Our team highlights the importance of the interactivity between consumers and virtual technology in shopping activities and to discuss the future directions of technology development of shopping practices in virtual environments. The discussion is organized into three sections. First, our team delineates the core assumption in understanding the relationships between virtual technology and consumers. Second, we investigates virtual technology in shopping practices from the use of reviewing prior research and to highlight three important areas for investigation, (1) the instrumental relation between the technology and consumer (I-It relation), (2) the connectivity to consumer (I-Other relation) and (3) the consumers' perception of shopping in virtual environments and daily practices in bricks-and-mortar shopping (I-World relation). Third, the article concludes with the contribution on the future technology development of virtual reality in shopping practices and to urge the needs of investigating shopping experiences in virtual worlds.

\section{Relationships between Consumers and Virtual Technology}


In understanding the use of virtual technology in shopping practices, many research focus on how consumers interact within the virtual environments of shopping activities. Scholars indicate that the advantage of virtual technology, especially immersive virtual technology, is to induce the sense of "being there", known as presence, of consumers [19, 41-43]. Researchers agree that the design of virtual technology brings the experience of presence to the fore as an important issue [21, 43-47]. Presence is the sensation experienced in virtual technology [44], insofar as the consumer is engrossed and immersed spontaneously in the virtual environments. Riva et al. [44] suggested that two themes are commonly found in the study of this phenomenon. On one hand, scholars claimed that presence is the inner experience or psychological states of the consumer using virtual technology. It is not requisite to associate with the consumers' experience of utilizing the technological medium. Therefore, the goal of utilizing virtual technology is to build up the sensational experience of individual within virtual environments [46, 48-62]. On the other hand, Riva et al. [44] claimed that a group of scholars had delineated the experience of presence as "Media Presence" [55, 57, 63-71], insofar as they suggest that the study of the use of virtual technology should focuses partly on consumers' experiences and partly on the technology development. Those scholars suggest that the relationships between consumers' and virtual technology are closely associated.

The first vision focuses on the consumers' broad psychological phenomenon. Those studies suggest that it is not necessarily linked the consumers' experiences to the technological aspect of virtual technology [44]. Those studies claim that the term "presence" usually signifies the sense of "being there" of the consumers' experiences [46]. Lee [46] suggests that in the study of presence, scholars should focus on understanding the consumers' psychological state rather than the technological aspect. On the other hand, the second vision suggests that scholars should not underestimate the influence of virtual technology to the consumers' experiences as they are deeply correlated with each other. Schroeder [69-71] suggested that the experience of presence in virtual environment is always partly doing with the consumers' state of mind and partly with the virtual technology, on the basis of which, a more immersive virtual technology would induce higher immersive experiences to consumers. Schroeder [69-71] highlights the importance of the relationships between virtual technology and consumer in understanding consumers' experiences and the use of virtual technology. In this paper, our team grounded on the media presence perspective to focus on the interaction between virtual technology and consumer by starting from the following statement:

virtual technology, as indicated by the definition given earlier, is about "being there": presence is therefore partly to do with the technology, and partly to do with the participants' state of mind [69].

It would be difficult to isolate the consumers' shopping experiences in virtual environments or the use of virtual technology as an isolated event which separated from its interaction. Therefore, the following discussion is focused on the interaction between virtual technology and consumers.

\section{Spotlight over the Shopping Practices in Virtual Worlds}

Based on the above assumption, our research team formulates the research framework in understanding consumers' shopping practices in virtual worlds. Our team focuses on the understanding the relationships between consumers and virtual technology by reviewing the prior research. Our team highlights the importance of the interaction between the consumers and virtual technology in three aspects, (1) the instrumental relations between the virtual technology and consumers; (2) the connectivity of consumers in virtual environments; and (3) the consumers' perception of shopping in virtual environments and daily practices in bricks-and-mortar shopping, which extend to a threefold model, namely I-It relation, I-Other relation and I-World relation respectively. The models are not formulated in neatly typologized, but rather, they are conceiving conceptual overlapping with each other. The following analysis brings the discussion from the respective theoretical issues to the practical application of virtual technology in shopping activities with the supplement of existing studies.

\subsection{I-It Relations - Instrumental Relations between Consumers and Virtual Technology in Shopping Activities}

I-It relation refers to the instrumental relations between virtual technology and consumer in shopping activities. Our team found that the prior research focus on understanding the instrumental relations between consumers and virtual technology in shopping practices which are related to (1) virtual environments development, (2) virtual objects development, (3) personalization, (4) sensorial enrichment, and (5) spatial interaction (Figure 1). The following analysis addresses the various aspects of each item.

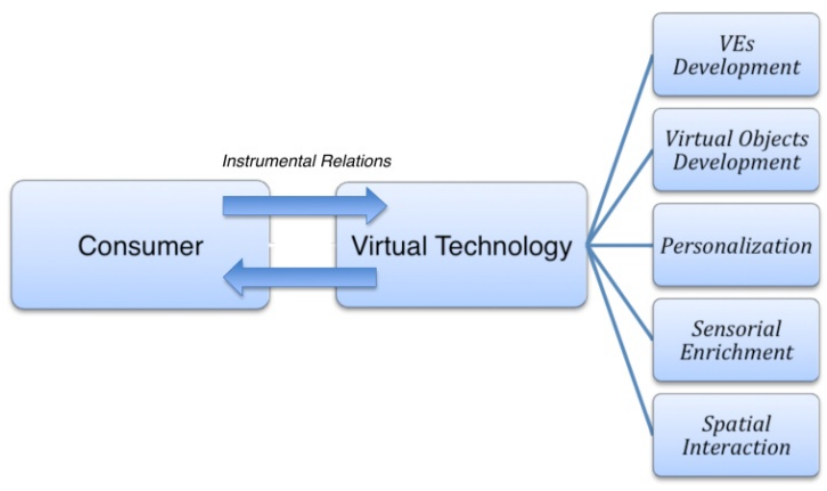

Figure 1. Instrumental relations of consumer and virtual technology

\subsubsection{Virtual Environments Development}


In the technology of developing virtual environments (VEs), scholars concern how these technologies emerge in shopping activities and its interaction with consumer in shopping activities. In understanding how the use of VEs technology affects consumers' shopping experiences, Tran [72] suggests that the use of $3 \mathrm{D}$ technological in $2 \mathrm{D}$ web-based environment is able in enhancing the consumers' perception and expectations. The interaction between consumer to $2 \mathrm{D}$ web-based environment and $3 \mathrm{D}$ virtual environments are inducing different consumers' shopping experiences through different dimension of stimulation. Li et al. [31] also compare the use of the technology of 2D product representation and the technology of the use of 3D product visualization, such as geometric and material product taxonomy. Based on the findings, Li et al. suggest a new type of product affordances, which names virtual affordances, in explaining the consumers' shopping experiences. Virtual technology enables in creating immersive virtual environments, which help to enrich users' telepresence experience. Huang et al. [73] suggest that numerous studies focus on flow experience in the effect of telepresence, systems' interface design and web characteristics in VEs. Immersive virtual environment is able to create unique telepresence experience, which different from other technology media. Huang and his colleague find that the text-based interaction systems would also enable in creating opportunities for flow experiences which is different from the telepresence experience in IVEs. With the advance of user experience, some researchers suggest that the technology of VEs would be benefit in marketing contribution. These researches focus on understanding how the interaction of consumer and VEs could contribute in marketing strategies. Gabisch and Gwebu [39] suggest that the emerging of the technology of VEs would be a new marketing channel as it brings unique experience to consumer, such as high level of interactivity and telepresence. Bulearca and Tamrjan [27] focus on examining how the use of augmented reality experiential marketing (AREM) would contribute in enhancing customer loyalty by increasing consumer satisfaction. Also, Bulearca and Tamrjan suggest that AREM would contribute in enhancing the intention of repetitive purchasing and positive word-of-mouth (WOM), which potential to bring a greater market share. Also, Srinivasan and Srivastave [74] investigate how VR is changing the future shopping practice by reshaping the consumers' shopping experience. They suggest that the use of VR technology as marketing tools would help to create consumers' experiences in retail segment by some important factor, such as the human interface. It helps to generate consumers' shopping experience, such as memorable experience. With the integration of E-commerce and VR technology, Pan et al. [75] claim that virtual experience could induce consumers' experience in perceiving product presentation.

\subsubsection{Virtual Objects Development (e.g. Virtual Product)}

The technology of virtual environment is the ground of arena which enables consumer to interact within a virtual shopping space. Besides the above technologies, some research focus on the investigation on the interaction between consumer and the virtual object within VEs, such as the virtual product in shopping activities. Wang et al. [76] develop the virtual technology of virtual handbag system in fashion retailing business. With the equipment of Kinect, rendering computer, webcam and TV screen, Wang and his colleague developed the virtual handbag system. Though the TV screen display, consumer could virtually try-on the handbags, including rotating the virtual handbags and scaling the handbags. The virtual handbag system aims to contribute on enhancing consumers' online shopping experience. In further investigating the adoption of virtual try-on technology, Kim and Forsythe [77] suggest that there are no significant gender differences in the use of virtual try-on in apparel shopping. Previous research suggests that the future development of virtual try-on technology in apparel shopping could focus on different gender. Other than applying virtual try-on in apparel industry, numerous researches focus on the interaction between consumer and virtual products presentation in virtual environments $[75,78]$. Schlosser [78] investigates that interaction between the presentation of virtual product and the consumers' purchasing intentions and suggest how the virtual product presentations could increase the consumers' purchasing intentions. Also, Park et al. [5] find that rotation has strong positive impact on consumers' perception of production information, mood, attitude and purchase intention. On the other hand, researchers also focus on the application of augmented technology system in shopping practice. Yang et al. [79] propose a AR system for fashion business which is able for low cost system installation with limited Internet downloading speeds. The effective time management enables to enhance consumers' hedonic shopping experience by reducing waiting time. Also, Cheng et al. [80] propose a AR system which develop a convenient and friendly virtual fashion show room for consumer. The virtual show room enable in generate $3 \mathrm{D}$ garment by $2 \mathrm{D}$ garment photos instead of 2D CAD patterns.

\subsubsection{Personalization}

Digital shopping enables in providing personal recommendation to consumer. With the application of virtual technology, personal shopping recommendation could advance to higher degree of interactivity. Virtual technology enables the function of shopping assistant, such as sales-avatar, which would bring higher interactivity between the consumer and virtual technology. Corvello et al. [17] conduct a psychological study of investigating the impact of anthropomorphic virtual shopping assistant (VSA), which is based on a knowledge management system. $\mathrm{Xu}$ and $\mathrm{Yu}$ [81] propose a system of personalized assistant, which is able in supporting personalized recommendation by data mining techniques. The aim is to enhance a human like shopping experience, which the shopping assistant could interact with 
the consumer. With the use of data mining techniques, some research focus on the interaction between the consumer experience and the product searching technology in virtual environments. Zhu et al. [82] propose the AR shopping assistant which is called PromoPad. PromoPad is able in enhancing consumers' shopping experiences with the suggestion of complementary products. Also, Iyer and Pazgal [83] propose the technology of Internet Shopping Agent (ISAs) which allow consumer to search many retailers for the lowest price products. Moreover, the different spatial experience and interactivity to physical shopping environment enables virtual shopping space to provide different product information searching experience. For instance, as mentioned before, the personalized assistant enable human like shopping experience in interacting with consumer, as it supports personalized recommendations by data mining techniques [81]. Mahmud et al. [84] also propose a system which enables information sharing between virtual world system and web application. Mathwick and Rigdom [85] conduct a research on the investigation in online product searching experience with the theory of flow experience.

\subsubsection{Sensorial Enrichment}

Some scholars focus on understanding how the interaction between consumer and virtual technology could enhance consumers' shopping experiences through the enrichment of sensation. Jin and Sung [23] investigate the impact of spoke sales-avatar and suggest that the auditory experience is able in enhancing consumers' shopping experiences. The findings show that the sincere spoke-avatars have several impacts on the consumer during the interaction. Jin and Sung claim that the consumer would turn out to have greater source expertise. Moreover, there is positive impact on the brand perception and increasing trustworthiness on the brand, which help to induce consumers' shopping intention. Also, the greater modality richness induces high consumers' involvement [24]. Besides the interaction with avatar shopping assistant, the store layout could also induce consumers' sensation experience. In virtual shopping, consumers would perceive the atmosphere of store layout though sensation. Vrechopoulos et al. [86] also suggest that the atmospheric of virtual store layout significantly affect consumer behavior, including the consumer action and their purchasing intentions.

\subsubsection{Spatial Operation}

Virtual technology is advanced in real-time rendering digital surroundings. The rendered VEs are able to induce different spatial experience with different controlling systems which are different from the actual world. Different virtual shopping space enables different spatial control, such as walking alone in virtual store, looking around within virtual store and picking up virtual product. The controlling system is closely affecting the consumers' shopping experience, as the consumer should interact with the virtual environments through the controlling system. Moreover, one of the characteristics of virtual technology is that enable to create three-dimensional spatial experience, which induces different spatial experience with 2D web-based shopping and actual world shopping. Therefore, many studies focus on understanding the interaction between the consumer and the spatial controlling system of virtual technology. Also, Couture et al. [87] indicate that virtual web shopping environments could be developed by HTML, with the use of discrete perspective displays. Vrechopoulos et al. [86] suggest that with the use of virtual setting, difference layout of virtual store could result different spatial experience which could induce different consumer action and behavior. Tlauka et al. [88] conduct a research in virtual shopping center, and discover that there are no significant gender differences in spatial performance, including navigation and wayfinding.

\subsection{I-other Relations - Connected with Consumers}

I-Other relation refers to the human interaction between consumers and also the consumers with marketers in the virtual communicative time and space. Compared with other forms of communication, such as text messages, email, and telephone, VR technology is advanced in creating telepresence experiences. VR enables a 3D virtual shopping arena to be created for shopping activities, while the traditional 2D shopping website does not. The expansion of the Internet, mobile networking and functional smart phone has enabled consumers to interact with others as if they are "being there together" anytime and everywhere [89]. The following analysis focus on the human interaction between the marketers to consumer and consumer to consumer within virtual communities related to (1) dissemination, (2) trustfulness, (3) social structure, (4) consumers' social presence and (5) virtual communities (VCs) as marketing tools (Figure 2).

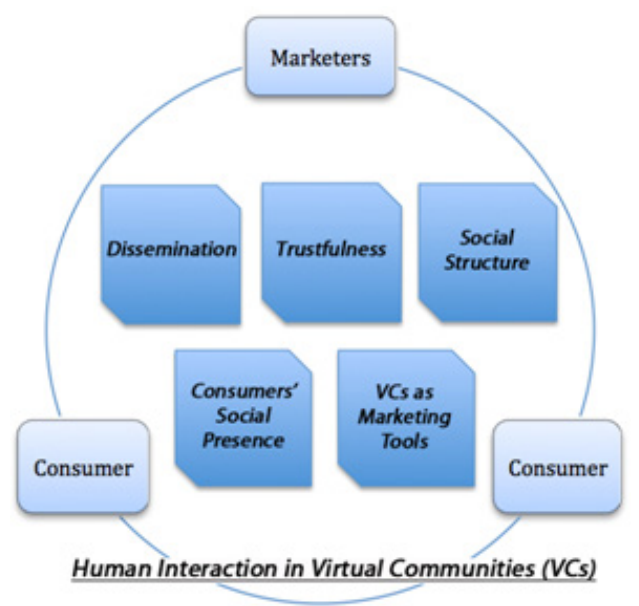

Figure 2. Human interaction in virtual communities

\subsubsection{Dissemination on Virtual Communities}

Virtual technology enables unique form of time and space in shopping arena for consumer, which is different from 2D 
web-based shopping and actual world shopping. In virtual environments, user could interact with other individuals in virtual communities (VCs). The virtual community is viewed as a social group, the society is organized largely on the basis of individuals' habit, taste and interests. Different virtual community has different ways of living, user could interact with each other with similar interests and sharing with each others as if a collective we. Numerous studies investigate how virtual communities enable to disseminate product and brand information to the targeted customers. Chen et al. [89] conduct a research on a peer-to-peer problem solving virtual communities (P3VC). Chen et al. investigated the constitution of the virtual communities' members' attitude and how the members intend to contribute knowledge within the virtual communities. Molesworth [90] suggests that in-game environment enables for brand placement which could improve consumers' perception on brand realism and allowing consumers to create consumption daydream. Besides understanding the interaction in virtual communities, some research focus on virtual communities' brand experience. Gabisch and Gwebu [39] investigate how consumers in virtual communities learn brands through their experience, which involve functional and social interaction. Also, Hsiao and Chiou [91] suggest that community loyalty is affected by social capital in virtual communities. Consumers' product knowledge and brand knowledge could be conceived as their social capital in the particular social structure. In virtual community, marketing contents could be widely contributed by consumers, such as Twitter, Facebook, Youtube and Wikipedia. However, Heinonen [92] suggests that consumers on social media are not as active as previous studies have been suggested. Based on the interview with consumers, Heinonen uncovers the managerial challenges of virtual communities and claim that virtual communities should reinforce consumers' motivation through entertainment, social connection and providing information.

\subsubsection{Trustfulness on Virtual Communities}

As long as the consumer could interact with others within virtual community, consumer could achieve a great amount of information and could even involve consumption and transaction. Therefore, the issue of trustfulness on virtual communities arises. Trustfulness of consumer on virtual communities involves the trustworthiness of online information, privacy, company policy and the confidence with retailer and marketer. In understanding the trust factor of consumer, Wu et al. [93] investigate how the trust factors influence virtual community member. The result of $\mathrm{Wu}$ et al.'s research shows that the members' shared values have affirmative effect on relationship commitment and trust. The members' antecedent satisfactions also have positive effect on the level of trust, relationship commitment and member stickiness. Wu et al. claim that the provided privacy policies of virtual community could increase the consumers' level of trust and the consumers' trust will have positive effect on the member stickiness and commitment. Nevertheless, Kim and Jin [29] provide a synthesizing overview on a total virtual communities which hosted by apparel retailers. The result shows that the membership policy is one of the keys elements to consumers' trustfulness.

\subsubsection{Social Structure on Virtual Communities}

Virtual community could be seen as a form of society which able in gathers consumers with similar interest. Some research focus on understanding the relational structure among social groups on virtual communities. Based on the society of virtual communities, researchers investigate the consumer human interaction within the social structure of virtual communities. Mathwick et al. [94] suggest that the communities' relational norms affect the social capital within virtual community with particular social structure. Within the virtual community the impacts of social trust, reciprocity, and voluntarism are reflected by the social capital. Further understanding the agency of customer in virtual community, Dholakia et al. [95] provide a social influence model. It is a model of user engagement in network-and-small-group-based VCs. The study investigated two group-level determinants, one of these is social identity and group norms; and the others are the consumers' motivational antecedent and mediators. In understanding the dynamic structure of $\mathrm{VCs}$, Chan and $\mathrm{Li}$ [32] proposed two different kinds of interactivity, which are structural interactivity and experiential interactivity. The finding shows that commitment and reciprocity within the social structure of VCs are affected by the suggested interactivity.

\subsubsection{Consumers' Social Presence in Virtual Communities}

In virtual communities, the human interaction between consumer to marketer and consumer to consumer involves the process of communication. The communication within virtual communities is interpersonal or interparty involved, because it involve different virtual worlds users and parties, such as business parties. Therefore, research focus on understanding the consumers' social presence in virtual communities, which evoke the awareness of other person within the communities. The way consumers interact with other consumer or takes any action within virtual community is affected by their social presence. Shin and Shin [96] claim that the consumer perceived social presence is the key factor to enhance consumers' behavioral attitude and perception of security in virtual shopping platforms of the consumers' virtual shopping activities. Hemp [97] also suggest that when consumer inhabit within virtual community, the application of avatar is able for consumer to identify and build up the consumers' social identity in VWs. Hemp claim that the avatar-based marketing could contributes in company segment, reach and influence potential consumers, insofar as the VWs could provide specific experience within virtual communities.

\subsubsection{Reaching Potential Consumers, Virtual Communities as Marketing Tools}

As virtual communities are able to gather consumers with similar habit, taste and interests, it could be used as the 
marketing tools for reaching potential target consumers. Füller and Matzler [98] propose a system for virtual customer integration. This virtual interaction tools are able to provide virtual experiences and help consumer to transfer their explicit and implicit innovative idea to the company's R\&D team. It contributes in enhancing consumers' interaction and helps to improve consumer relationship. Sangwan [99] also conduct a research to investigate what factor motivate $\mathrm{VC}$ member to engagement in a virtual community and suggest that the virtual initiator provided by member for other consumer is an important factor for the interaction. On the other hand, Gabisch and Gwebu [39] claim that both functional and social interaction $\mathrm{n}$ between consumers in virtual communities could contribute in enhancing consumer brand knowledge.

\subsection{I-World Relations - Synthesizing Virtual Shopping and Real World Shopping}

I-World relation refers to the consumers' perception of shopping practices in VEs and daily practices in bricks-and-mortar shopping. The mentioned area focuses on understanding the consumers' perception in combining virtual worlds (virtual shopping experiences) and actual world (bricks-and-mortar shopping experiences). For instance, AR technology is specifically blurring the border of the consumers' perceiving experience between virtual shopping experience and bricks-and-mortar shopping experience. AR technology is advanced in augmenting consumers' experience, such as providing virtual information (i.e. product information, promotional information and product recommendation) to consumers' daily shopping through virtual platform. The following discussion addresses I-World relations in three aspects.

\subsubsection{Consumer Perception of Virtual Products in Shopping Space}

In virtual shopping space, immersive virtual environments enable to induce consumer to perceive virtual object (e.g. virtual product) as if actual object [46]. Therefore, numerous studies focus on understanding the consumers' perception of virtual objects from the interaction between virtual technology and consumer. Huang [100] draw the theory form environmental psychology to investigate the relationships between consumers' purchasing intention and the interaction features on consumers' online experiences. As the consumers' perceptions of virtual product affect their purchase intention, scholars investigate the impact of the imaging of virtual object in shopping practices. Tran [72] investigates the influence of consumers' experiences and expectations in perceiving digital composed 3D product in virtual worlds and the product photograph on $2 \mathrm{D}$ online shopping websites. Song et al. [101] suggest that telepresence and fantasy and two important factors for consumers in perceiving virtual product in online apparel shopping experience. They find that the imagery pleasurable experience of product use could be entailed by fantasy. In examining the imagery of consumer, Schlosser [78] claim that the high level of interactivity could induce consumer memory association than static text and picture. Fiore et al. [102] find that the consumers' experience of telepresence, VEs' instrumental and experiential values would be produced by the consumers' responses. Nevertheless, for the investigation of consumers' perception on virtual product and actual product, Li et al. [103] examine the different between the consumers" perception on 2D product representations to 3D product visualization, and propose an alternative product affordances, the virtual affordances. Moreover, Lee and Chung [28] found that the interface of virtual shopping platform has positive effect on consumer satisfaction which compare to ordinary shopping mall. The three explanatory variables, including conveniences, quality assurances, and enjoyments are improved in the virtual platform.

\subsubsection{Shopping Intention in Virtual Environments}

Virtual shopping environment enable to induce different shopping experiences which compare to ordinary shopping space, such as bricks-and-mortar shopping and 2D websites online shopping. Many research focus on understanding how the consumer perception of shopping intention in virtual shopping is different. Domina et al. [104] examine the factors affecting consumer shopping intention in virtual worlds. Domina et al. find that enjoyment of consumers perceived experience positively affect their shopping intention, and the consumer innovativeness is an external factor indirectly effect consumer experience of enjoyment and concentration. Lee et al. [16] conduct a research of consumers' perceived experience in Second Life. They report that to compare with other model constructs, perceived control and enjoyment are significantly stronger elements to influence consumers' shopping intention in virtual worlds. Lau et al. [18] suggest that the support of telepresence and enjoyment experience in virtual shopping could enhance consumers' perceived shopping experience. On the other hand, Lee et al. [16] report that telepresence and perceived concentration have limited effect on consumers' shopping intention in VWs, which put the issue of the importance of telepresence in virtual shopping in debate. Further investigation on consumers' satisfaction in virtual shopping, Lee [28] report that consumer perceive virtual product in virtual shopping mall's user interface could enhance their satisfaction of shopping activities. Some research focus on the complexity of consumer's behavior in 3D virtual worlds in relations to consumer perceived experience [78, 105-107]. Chen et al. [106] investigate the relation between virtual experiential marketing (VEM) and customer intentions and loyalties which focus on how different between consumers perceive virtual product in virtual worlds and actual product in bricks-and-mortar shopping. Schlosser [78] also find that the presentation of product in virtual environments could improve the consumer purchase intentions. Also, Huang [100] find that the consumer emotional effects in virtual shopping activities 
influence their virtual exploratory and shopping decisions.

\subsubsection{Between Bricks-and-mortar Shopping and Virtual Shopping}

Many research focus on the understanding of the relations between Bricks-and-mortar shopping and virtual shopping, such as virtual worlds purchase and real world purchase. Gabisch and Gwebu [39] investigate the multichannel effect of using VR technology in shopping practice and the relations between virtual brands experience and real-world purchasing decisions. Gabisch and Gwebu find that the advantages of using virtual shopping experience as marketing channel are the accuracy and useful for evaluation. Gabisch [40] further report that VWs brand experiences could have positive effect on the consumers' perception on real world purchasing intention. On the other hand, some research focus on the virtual store layout design and shopping assistant function. Jin and Bolebruch [108] conduct a research which applies a spoke-avatar shopping assistant with characteristics in terms of humanness. Jin and Bolebruch report that the humanness assistant has positive effect on the consumer perception of advertising message. For the virtual store layout design, Tlauka et al. [88] report that to compare the consumers' spatial performance in real world and virtual shopping arena, there is no significant gender different, such navigating and wayfinding.

\section{Conclusion}

This article reviews prior research on the scope of using virtual technology in shopping practices and suggests that future development direction of virtual technology should focus on the interaction between consumer and virtual technology. Therefore, our research team aims to trigger further investigations in the areas of interaction between consumer and virtual technology in three ways, (1) the instrumental relations between the virtual technology and consumers (I-It relation); (2) the connectivity of consumers in virtual environments (I-Other relation); and (3) the consumers' perception of shopping practices in virtual worlds and daily practices in bricks-and-mortar shopping. This agenda aims to contribute for future development on virtual technology in shopping practices and to suggest a viable research direction for further investigation on this topic. Future investigation may take correlation research approach with the factors of prior research which suggested earlier by this article. Also, this article provides a thematic review to state basic research interests of the use of virtual technology in shopping practices. Future research could be developed based on the suggested direction and to compare with others. Those results could be utilized for hypothesis for further testing. Further investigation on this topic could be addressed in the future research to optimize the research area and technology development.

\section{Acknowledgements}

We are very grateful to experts for the appropriate and constructive suggestions to improve this research.

\section{REFERENCES}

[1] S. Ha and L. Stoel. Online apparel retailing: roles of e-shopping quality and experiential e-shopping motives, Journal of Service Management, Vol.23, No.2, p. 197-215, 2012.

[2] U.M. Dholakia, B.E. Kahn, R. Reeves, A. Rindfleisch, D. Stewart, and E. Taylor. Consumer behavior in a multichannel, multimedia retailing environment, Journal of Interactive Marketing, Vol.24, No.2, p. 86-95, 2010.

[3] P. Huang, N.H. Lurie, and S. Mitra. Searching for experience on the web: An empirical examination of consumer behavior for search and experience goods, Journal of Marketing, Vol.73, No.2, p. 55-69, 2009.

[4] D. Grewal, M. Levy, and V. Kumar. Customer experience management in retailing: An organizing framework, Journal of Retailing, Vol.85, No.1, p. 1-14, 2009.

[5] J. Park, L. Stoel, and S.J. Lennon. Cognitive, affective and conative responses to visual simulation: The effects of rotation in online product presentation, Journal of Consumer Behaviour, Vol.7, No.1, p. 72-87, 2008.

[6] L. Esbjerg, B.B. Jensen, T. Bech-Larsen, M.D. de Barcellos, Y. Boztug, and K.G. Grunert. An integrative conceptual framework for analyzing customer satisfaction with shopping trip experiences in grocery retailing, Journal of Retailing and Consumer Services, Vol.19, No.4, p. 445-456, 2012.

[7] S.-E. Byun and M. Mann. The Influence of Others The Impact of Perceived Human Crowding on Perceived Competition, Emotions, and Hedonic Shopping Value, Clothing and Textiles Research Journal, Vol.29, No.4, p. 284-297, 2011.

[8] A. Borges, J.-C. Chebat, and B.J. Babin. Does a companion always enhance the shopping experience?, Journal of Retailing and Consumer Services, Vol.17, No.4, p. 294-299, 2010 .

[9] M.J. Arnold and K.E. Reynolds. Approach and Avoidance Motivation: Investigating Hedonic Consumption in a Retail Setting, Journal of Retailing, Vol.88, No.3, p. 399-411, 2012.

[10] M. Moynagh and R. Worsley. Tomorrow's consumer - The shifting balance of power, Journal of Consumer Behaviour, Vol.1, No.3, p. 293-301, 2002.

[11] C.K. Prahalad and V. Ramaswamy. Co-creating unique value with customers, Strategy \& Leadership, Vol.32, No.3, p. 4-9, 2004.

[12] R.V. Kozinets, Brands in space: New thinking about experiential retail, in Brick \& Mortar Shopping in the 21st Century, T.M. Lowrey, Editor 2008, Lawrence Erlbaum Associates: Mahwah, NJ. p. 3-15. 
[13] V.C.S. Diep and J.C. Sweeney. Shopping trip value: Do stores and products matter?, Journal of Retailing and Consumer Services, Vol.15, No.5, p. 399-409, 2008.

[14] M. Holzwarth, C. Janiszewski, and M.M. Neumann. The influence of avatars on online consumer shopping behavior, Journal of Marketing, Vol.70, No.4, p. 19-36, 2006.

[15] H.F. Lau, K.W. Lau, and C.W. Kan. Exploring Consumers' Virtual Shopping Experience in Virtual Reality. in The 2012 International Congress on Engineering and Information (ICEAI 2012). Shanghai. 2012.

[16] S.-E. Lee, T. Domina, and M. MacGillivray. Exploring consumers' flow experiences in virtual shopping: an exploratory study, International Journal of Electronic Marketing and Retailing, Vol.4, No.2, p. 165-182, 2011.

[17] V. Corvello, E. Pantano, and A. Tavernise, The Design of an Advanced Virtual Shopping Assistant for Improving Consumer Experience, in Advanced Technologies Management for Retailing: Frameworks and Cases, E. Pantano and H. Timmermans, Editors. 2011, IGI Global. p. 70-86.

[18] K.W. Lau, P.Y. Lee, and C.W. Kan. From distance shopping to virtual shopping, International Journal of Design Sciences and Technology, Vol.17, No.2, p. 77-90, 2010.

[19] A. Haans and W.A. IJsselsteijn. Embodiment and Telepresence: Toward a Comprehensive Theoretical Framework, Interacting with Computers, Vol.24, p. 211-218, 2012.

[20] M.Y. Hyun and R.M. O'Keefe. Virtual destination image: Testing a telepresence model, Journal of Business Research, Vol.65, No.1, p. 29-35, 2012.

[21] G. Riva. Virtual reality and telepresence, Science, Vol.318, No.5854, p. 1240-1242, 2007.

[22] A. Mollen and H. Wilson. Engagement, telepresence and interactivity in online consumer experience: Reconciling scholastic and managerial perspectives, Journal of Business Research, Vol.63, No.9, p. 919-925, 2010.

[23] S.-A.A. Jin and S. Yongjun. The roles of spokes-avatars' personalities in brand communication in $3 \mathrm{D}$ virtual environments, Journal of Brand Management, Vol.17, No.5, p. $317-327,2010$.

[24] S.-A.A. Jin. The Roles of Modality Richness and Involvement in Shopping Behavior in 3D Virtual Stores, Journal of Interactive Marketing, Vol.23, No.3, p. 234-246, 2009.

[25] M. Catterall and P. Maclaran. Researching consumers in virtual worlds: A cyberspace odyssey, Journal of Consumer Behaviour, Vol.1, No.3, p. 228-237, 2002.

[26] C.-k. Shen and S. Liu. Study of Virtual Reality (VR) being Used in the Online Shopping, Science \& Technology Information, Vol.1, p. 112, 2012.

[27] M. Bulearca and D. Tamarjan. Augmented Reality: A Sustainable Marketing Tool?, Global Business and Management Research: An International Journal, Vol.2, No. 2 \& 3, p. 237-252, 2010.

[28] K.C. Lee and N. Chung. Empirical analysis of consumer reaction to the virtual reality shopping mall, Computers in
Human Behavior, Vol.24, No.1, p. 88-104, 2008.

[29] H.-S. Kim and B. Jin. Exploratory study of virtual communities of apparel retailers, Journal of Fashion Marketing and Management, Vol.10, No.1, p. 41-55, 2006.

[30] P.M.C. Swatman and C.Y.P. Chin. The Virtual Shopping Experience: Virtual Presence as a Motivator for Online Shopping, Deakin University School of Information Systems Working Paper, Vol.No.2003/24, 2004.

[31] H. Li, T. Daugherty, and F. Biocca. The Role of Virtual Experience in Consumer Learning, Journal of Consumer Psychology, Vol.13, No.4, p. 395-407, 2003.

[32] K.W. Chan and S.Y. Li. Understanding consumer-to-consumer interactions in virtual communities: The salience of reciprocity, Journal of Business Research, Vol.63, No.9, p. 1033-1040, 2009.

[33] F.F.H. Nah, B. Eschenbrenner, and D. DeWester. Enhancing Brand Equity Through Flow and Telepresence: A Comparison of 2D and 3D Virtual Worlds, MIS Quarterly-Management Information Systems, Vol.35, No.3, p. 731, 2011 .

[34] N. Berente, S. Hansen, J.C. Pike, and P.J. Bateman. Arguing the Value of Virtual Worlds: Patterns of Discursive Sensemaking of an Innovative Technology, MIS Quarterly-Management Information Systems, Vol.35, No.3, p. 685,2011 .

[35] T. Kohler, J. Fueller, K. Matzler, and D. Stieger. Co-creation in virtual worlds: the design of the user experience, MIS Quarterly, Vol.35, No.3,p. 773-788, 2011.

[36] L. Goel, N.A. Johnson, I. Junglas, and B. Ives. From Space to Place: Predicting Users' Intentions to Return to Virtual Worlds, MIS Quarterly-Management Information Systems, Vol.35, No.3, p. 749, 2011.

[37] C. Saunders, A.F. Rutkowski, M. van Genuchten, D. Vogel, and J.M. Orrego. Virtual Space and Place: Theory and Test, Management Information Systems Quarterly, Vol.35, No.4, p. 1079-1098, 2011

[38] E. Huang. Online experiences and virtual goods purchase intention, Internet Research, Vol.22, No.3, p. 252-274, 2012.

[39] J.A. Gabisch and K.L. Gwebu. Impact of virtual brand experience on purchase intentions : The role of multichannel congruence, Journal of Electronic Commerce Research, Vol.12, No.4, p. 302-319, 2011.

[40] J.A. Gabisch. Virtual world brand experience and its impact on real world purchasing behavior, Journal of Brand Management, Vol.19, No.1, p. 18-32, 2011.

[41] A. Faiola, C. Newlon, M. Pfaff, and O. Smyslova. Correlating the effects of flow and telepresence in virtual worlds: Enhancing our understanding of user behavior in game-based learning, Computers in Human Behavior, Vol.29, No.3, p. 1113-1121, 2013.

[42] M.P. McCreery, P. Schrader, S.K. Krach, and R. Boone. A sense of self: The role of presence in virtual environments, Computers in Human Behavior, Vol.29, No.4, p. 1635-1640, 2013.

[43] S.E. Kober and C. Neuper. Personality and Presence in Virtual Reality: Does their Relationship depend on the used 
Presence Measure?, International Journal of Human-Computer Interaction, Vol.29, No.1, p. 13-25, 2012.

[44] G. Riva, J.A. Waterworth, E.L. Waterworth, and F. Mantovani. From intention to action: The role of presence, New Ideas in Psychology, Vol.29, No.1, p. 24-37, 2011.

[45] F. Biocca. The cyborg's dilemma: Embodiment in virtual environments, Journal of Computer-Mediated Communication, Vol.3, No.2, p. 1-29, 1997.

[46] K.M. Lee. Presence, explicated, Communication Theory, Vol.14, No.1, p. 27-50, 2004.

[47] D. Mestre and J.L. Vercher, Immersion and presence, in Virtual Reality: Concepts and Technologies, P. Fuchs, G. Moreau, and P. Guitton, Editors. 2011, CRC Press, Inc. p. 93-100.

[48] R.M. Baños, C. Botella, A. Garcia-Palacios, H. Villa, C. Perpina, and M. Alcaniz. Presence and reality judgment in virtual environments: A unitary construct?, CyberPsychology \& Behavior, Vol.3, No.3, p. 327-335, 2000.

[49] K.M. Lee. Why presence occurs: Evolutionary psychology, media equation, and presence, Presence: Teleoperators \& Virtual Environments, Vol.13, No.4, p. 494-505, 2004.

[50] G. Mantovani and G. Riva. "Real" presence: How different ontologies generate different criteria for presence, telepresence, and virtual presence, Presence, Vol.8, No.5, p. 540-550, 1999.

[51] T. Schubert, F. Friedmann, and H. Regenbrecht. The experience of presence: Factor analytic insights, Presence: Teleoperators \& Virtual Environments, Vol.10, No.3, p. 266-281, 2001.

[52] A. Spagnolli and L. Gamberini. Immersion/Emersion: Presence in hybrid environments. in Proceedings of the fifth annual international workshop, Presence. Porto, Portugal. 2002.

[53] J.A. Waterworth and E.L. Waterworth. The meaning of presence, Presence-Connect, Vol.3, No.2, 2003.

[54] P. Zahorik and R.L. Jenison. Presence as being-in-the-world, Presence, Vol.7, No.1, p. 78-89, 1998.

[55] T.B. Sheridan. Musings on telepresence and virtual presence, Presence: Teleoperators and Virtual Environments, Vol.1, No.1, p. 120-126, 1992.

[56] R. Baños, C. Botella, and C. Perpiñá. Virtual reality and psychopathology, CyberPsychology \& Behavior, Vol.2, No.4, p. 283-292, 1999.

[57] T. Marsh, P. Wright, and S. Smith. Evaluation for the design of experience in virtual environments: modeling breakdown of interaction and illusion, Cyberpsychology \& Behavior, Vol.4, No.2, p. 225-238, 2001.

[58] K. Moore, B.K. Wiederhold, M.D. Wiederhold, and G. Riva. Panic and agoraphobia in a virtual world, CyberPsychology \& Behavior, Vol.5, No.3, p. 197-202, 2002.

[59] G. Riva and F. Davide. Communications through virtual technologies: Identity, community and technology in the communication age. Vol. 1. Ios PressInc, 2001.

[60] G. Riva, F. Davide, and W. IJsselsteijn. Being there:
Concepts, effects and measurements of user presence in synthetic environments, ed. G. Riva, F. Davide, and W. IJsselsteijnIos Press. Amsterdam, 2003, 3-16.

[61] A. Spagnolli, L. Gamberini, and D. Gasparini. Breakdown analysis in virtual reality usability evaluation, PsychNology Journal Educational Computing Research, Vol.1, No.1, 2003.

[62] E.L. Waterworth and J.A. Waterworth. Focus, locus, and sensus: The three dimensions of virtual experience, CyberPsychology \& Behavior, Vol.4, No.2, p. 203-213, 2001.

[63] W. IJsselsteijn, H. de Ridderb, J. Freemanc, and S. Avonsd. Presence: Concept, determinants and measurement, 2000.

[64] M. Lombard and T. Ditton. At the heart of it all: The concept of presence, Journal of Computer-Mediated Communication, Vol.3, No.2, p. 0-0, 1997.

[65] J.M. Loomis. Distal attribution and presence, Presence: Teleoperators and Virtual Environments, Vol.1, No.1, p. 113-119, 1992.

[66] W.J. Sadowski and K.M. Stanney, Measuring and managing presence in virtual environments, in Handbook of virtual environments technology2002, Lawrence Erlbaum Associates: Mahwah, NJ.

[67] D.W. Schloerb. A quantitative measure of telepresence, Presence: Teleoperators and Virtual Environments, Vol.4, No.1, p. 64-80, 1995.

[68] T.B. Sheridan. Further musing on the psychophysics of presence, Presence, Teleoperators, and Virtual Environments, Vol.5, p. 241-246, 1996.

[69] R. Schroeder. Social interaction in virtual environments: Key issues, common themes, and a framework for research, The social life of avatars: Presence and interaction in shared virtual environments, Vol., p. 1-18, 2002.

[70] R. Schroeder. Being there together: social interaction in virtual environmentsOxford University Press. London, 2011.

[71] R. Schroeder. Being there together and the future of connected presence, Presence: Teleoperators and Virtual Environments, Vol.15, No.4, p. 438-454, 2006.

[72] M.Q. Tran. Understanding the influence of 3D virtual worlds on perceptions of 2D e-commerce websites. in Proceedings of the 2nd ACM SIGCHI Symposium on Engineering Interactive Computing Systems. 2010.

[73] L.-T. Huang, C.-A. Chiu, K. Sung, and C.-K. Farn. A Comparative Study on the Flow Experience in Web-Based and Text-Based Interaction Environments, CyberPsychology, Behavior, and Social Networking, Vol.14, No.1-2, p. 3-11, 2011.

[74] S.R. Srinivasan and R.K. Srivastava. Creating the futuristic retail experience through experiential marketing: Is it possible \& quest; An exploratory study, Journal of Retail \& Leisure Property, Vol.9, No.3, p. 193-199, 2010.

[75] Z.-g. Pan, T. Chen, M.-m. Zhang, and B. Xu. Virtual Presentation and Customization of Products Based on Internet, International Journal of CAD/CAM, Vol.4, No.1, 2009. 
[76] L. Wang, R. Villamil, S. Samarasekera, and R. Kumar. Magic Mirror: A virtual handbag shopping system. in Computer Vision and Pattern Recognition Workshops (CVPRW), 2012 IEEE Computer Society Conference on. 2012.

[77] J. Kim and S. Forsythe. Adoption of Virtual Try-on technology for online apparel shopping, Journal of Interactive Marketing, Vol.22, No.2, p. 45-59, 2008.

[78] A.E. Schlosser. Experiencing products in the virtual world: The role of goal and imagery in influencing attitudes versus purchase intentions, Journal of Consumer Research, Vol.30, No.2, p. 184-198, 2003.

[79] C.-Y. Yang, W.-K. Chiou, D.-H. Huang, Y.-T. Peng, B.-H. Chen, Y.-H. Yang, and P.-S. Tsai. Application of Virtual Reality Technology in Online Fashion Store Development. in Computational Intelligence and Software Engineering, 2009. CiSE 2009. International Conference on. 2009.

[80] C.-I. Cheng, D.S.-M. Liu, C.-H. Tsai, and L.-T. Chen. A 3D Virtual Show Room for Online Apparel Retail Shop. in Proceedings: APSIPA ASC 2009: Asia-Pacific Signal and Information Processing Association, 2009 Annual Summit and Conference. 2009.

[81] B. Xu and Y. Yu. A Personalized Assistant in 3D Virtual Shopping Environment. in 2010 Second International Conference on Intelligent Human-Machine Systems and Cybernetics. Nanjing, China. 2010.

[82] W. Zhu and C.B. Owen. Design of the PromoPad: An Automated Augmented-Reality Shopping Assistant, Journal of Organizational and End User Computing (JOEUC), Vol.20, No.3, p. 41-56, 2008.

[83] G. Iyer and A. Pazgal. Internet shopping agents: Virtual co-location and competition, Marketing Science, Vol.22, No.1, p. 85-106, 2003.

[84] J. Mahmud, Y.-W. Huang, J. Ponzo, and R. Pollak, Avara: a system to improve user experience in web and virtual world, in Proceedings of the 15th international conference on Intelligent user interfaces2010: Hong Kong, China. p. 349-352.

[85] C. Mathwick and E. Rigdon. Play, flow, and the online search experience, Journal of Consumer Research, Vol.31, No.2, p. 324-332, 2004.

[86] A.P. Vrechopoulos, R.M. O'Keefe, G.I. Doukidis, and G.J. Siomkos. Virtual store layout: An experimental comparison in the context of grocery retail, Journal of Retailing, Vol.80, No.1, p. 13-22, 2004.

[87] J.H. Couture, H.A. Colle, and G.B. Reid. Navigation fidelity in 3D perspective displays for web-based shopping: From nodes to views, International Journal of Human-Computer Interaction, Vol.19, No.2, p. 181-200, 2005.

[88] M. Tlauka, A. Brolese, D. Pomeroy, and W. Hobbs. Gender differences in spatial knowledge acquired through simulated exploration of a virtual shopping centre, Journal of Environmental Psychology, Vol.25, No.1, p. 111-118, 2005.

[89] G.-L. Chen, S.-C. Yang, and S.-M. Tang. Sense of virtual community and knowledge contribution in a P3 virtual community: Motivation and experience, Internet Research, Vol.23, No.1, p. 4-26, 2013.
[90] M. Molesworth. Real brands in imaginary worlds: Investigating players' experiences of brand placement in digital games, Journal of Consumer Behaviour, Vol.5, No.4, p. 355-366, 2006.

[91] C.-C. Hsiao and J.-S. Chiou. The effect of social capital on community loyalty in a virtual community: Test of a tripartite-process model, Decision Support Systems, Vol.54, p. $750-757,2012$.

[92] K. Heinonen. Consumer activity in social media: Managerial approaches to consumers' social media behavior, Journal of Consumer Behaviour, Vol.10, No.6, p. 356-364, 2011.

[93] J.-J. Wu, Y.-H. Chen, and Y.-S. Chung. Trust factors influencing virtual community members: A study of transaction communities, Journal of Business Research, Vol.63, No.9, p. 1025-1032, 2010.

[94] C. Mathwick, C. Wiertz, and K. De Ruyter. Social capital production in a virtual P3 community, Journal of Consumer Research, Vol.34, No.6, p. 832-849, 2008.

[95] U.M. Dholakia, R.P. Bagozzi, and L.K. Pearo. A social influence model of consumer participation in network-and small-group-based virtual communities, International Journal of Research in Marketing, Vol.21, No.3, p. 241-263, 2004.

[96] D.-H. Shin and Y.-J. Shin. Consumers' trust in virtual mall shopping: The role of social presence and perceived security, International Journal of Human-Computer Interaction, Vol.27, No.5, p. 450-475, 2011.

[97] P. Hemp. Avatar-based marketing, Harvard Business Review, Vol.84, No.6, p. 48-57, 2006.

[98] J. Füller and K. Matzler. Virtual product experience and customer participation - Chance for customer-centred, really new products, Technovation, Vol.27, No.6, p. 378-387, 2007.

[99] S. Sangwan. Virtual community success: A uses and gratifications perspective. in System Sciences, 2005. HICSS'05. Proceedings of the 38th Annual Hawaii International Conference on. 2005.

[100] M.-H. Huang. Modeling virtual exploratory and shopping dynamics: An environmental psychology approach, Information \& Management, Vol.41, No.1, p. 39-47, 2003.

[101] K. Song, A.M. Fiore, and J. Park. Telepresence and fantasy in online apparel shopping experience, Journal of Fashion Marketing and Management, Vol.11, No.4, p. 553-570, 2007.

[102] A.M. Fiore, J. Kim, and H.-H. Lee. Effect of image interactivity technology on consumer responses toward the online retailer, Journal of Interactive Marketing, Vol.19, No.3, p. 38-53, 2005.

[103] H. Li, T. Daugherty, and F. Biocca. Impact of 3-D advertising on product knowledge, brand attitude, and purchase intention: The mediating role of presence, Journal of Advertising, Vol., p. 43-57, 2002.

[104] T. Domina, S.-E. Lee, and M. MacGillivray. Understanding factors affecting consumer intention to shop in a virtual world, Journal of Retailing and Consumer Services, Vol.19, p. 613-620, 2012.

[105] A. Hendaoui and M. Limayem. Understanding consumer 
virtual shopping behavior in 3D virtual worlds: A theoretical and empirical investigation. in International Conference on Information Systems (ICIS). Paris. 2008.

[106] J. Chen, R.K. Ching, M.M. Luo, and C.-C. Liu. Virtual experiential marketing on online customer intentions and loyalty. in Hawaii International Conference on System Sciences, Proceedings of the 41st Annual. 2008.

[107] C. Chin and P. Swatman. The virtual shopping experience: Using virtual presence to motivate online shopping, Australasian Journal of Information Systems, Vol.13, No.1, 2005.

[108] S.-A.A. Jin and J. Bolebruch. Avatar-Based Advertising in Second Life: The Role of Presence and Attractiveness of Virtual Spokespersons, Journal of Interacive Advertising, Vol.10, No.1, p. 51-60, 2009. 